\title{
Application of CRISPR/Cas9 Technology in the Genetic Improvement of Rice Yield and Quality Characters
}

Bo Peng (Corresponding Author), Xiaorui Ma, Tao Yang, Mengyang Zheng College of Life Sciences and Institute for Conservation and Utilization of Agro-bioresources in Dabie Mountains, Xinyang Normal University, Xinyang, China

Juan Peng

Xinyang Station of Plant Protection and Inspection, Xinyang, China

Xiayu Tian,

College of Life Sciences and Institute for Conservation and Utilization of Agro-bioresources in Dabie Mountains, Xinyang Normal University, Xinyang, China

Xiaohua Song

Xinyang Academy of Agricultural Science, Xinyang, China

Ruihua Pang, Jintao Li, Quanxiu Wang, Wei Zhou

College of Life Sciences and Institute for Conservation and Utilization of Agro-bioresources in Dabie Mountains, Xinyang Normal University, Xinyang, China

\section{Xinxiang A (Corresponding Author)}

Yunnan Provincial Key Lab of Agricultural Biotechnology of Yunnan Academy of Agricultural Sciences \& Scientific Observation Station for Rice Resource of Yunnan, Ministry of Agriculture, Yunnnan Kunming, China

\section{Hongyu Yuan (Corresponding Author)}

College of Life Sciences and Institute for Conservation and Utilization of Agro-bioresources in Dabie Mountains, Xinyang Normal University, Xinyang, China 
Received: Mar. 29, 2020 Accepted: May 5, 2020

doi:10.5296/jbls.v11i2.17039 URL: https://doi.org/10.5296/jbls.v11i2.17039

\begin{abstract}
Rice (Oryza sativa L.) is one of the most important food crops in the world. With the continuous increase of global population and the continuous improvement of people's living standards, it has become the focus of attention of rice breeders and botanists to improve the yield and quality of rice. In the new genome editing technology, the CRISPR/Cas system can accurately and specifically edit the target genome region. In recent years, CRISPR/Cas9 technology has made important progress in studying the function of new genes, increasing rice yield and improving rice quality. Therefore, this paper mainly reviewed the application of CRISPR/Cas9 technology in the genetic improvement of rice yield and rice quality in recent years, and looked forward to the application prospect of CRISPR/Cas9 technology in rice genetic breeding, which will provide important reference for the cultivation of new high-quality and high-yield rice varieties.
\end{abstract}

Keywords: rice, CRISPR/Cas9, yield character, quality character, genetic improvement

\title{
1. Introduction
}

Rice (Oryza sativa L.) is one of the most important food crops in the world. It is the main food for more than 3 billion people in more than 100 countries and regions (Kusano et al., 2015; Peng et al., 2016a). The world population is expected to reach 10 billion by 2050. At that time, the global demand for agricultural products will increase by about $70 \%$, and the annual grain output will increase from the current 2.1 billion tons to about 3 billion tons (Romero and Gatica-Arias, 2019). With the continuous growth of the world population, the continuous reduction of cultivated land area, the gradual deterioration of ecological environment and other adverse factors, there is a greater risk for the sustainable and stable supply of global food. It is urgent to further improve the yield of rice to ensure global food security (He, 2014). In recent decades, with the continuous improvement of people's living standards, the demand for high-quality rice is also increasing (Peng et al., 2019). Therefore, increasing rice yield and improving rice quality are the focus of attention of rice breeders and botanists.

In recent years, various new technologies and methods have been gradually applied to the genetic improvement of main food crops, especially in the field of gene editing technology. New genome editing techniques have been developed to replace the previous techniques such as random mutagenesis, naturally occurring mutations and classical breeding techniques because these methodologies are time consuming and take too long to obtain individuals with the desired phenotype. New editing technique such as CRISPR/Cas9 has been successfully used in major crops and model plants due to its simplicity, adaptability, and high precision (Ma et al., 2015a Xu et al., 2016). CRISPR/Cas9 system is highly desirable for achieving the goal of rice grain quality improvement with more precision and higher efficiency. Whereas, 
the functions of various components of the rice genome ultimately enable the production of higher yielding varieties with better quality rice grains (Xi et al., 2015). In this review, we will focus on the use of CRISPR/Cas technique to improve desirable traits in rice, such as tolerance to biotic and abiotic stresses as well as different parameters involved in determining yield and quality. In addition, we will discuss the problems and prospects of this technique in rice.

\section{CRISPR/Cas9 Technology}

Gene editing technology is the technology of targeted modification of specific DNA sequence in genome, which includes gene targeting technology established in 1980s and a variety of new and efficient DNA targeting endonuclease technologies developed in recent years, such as ZFNs (zinc finger nucleases), TALEN (transcription activator-like effector nucleases) and CRISPR/Cas9 (clustered regularly interleaved short palindrome repeats) (Doudna et al., 2014; Romero and Gatica-Arias, 2019). In 1987, CRISPR/Cas was accidentally discovered in E. colie as an adaptive immune system capable of degrading exogenous DNA (Ishino et al., 1987). Later, it was also reported in other bacteria, including Shigella dysentery, Salmonella enteritidis and Mycobacterium tuberculosis (Nakata et al., 1989). But it wasn't until 2012 that anyone realized the potential of using CRISPR / Cas system for genome editing (Jinek et al., 2012).

DNA targeted endonuclease technology can repair damaged DNA by homologous recombination or non homologous terminal connection by breaking double strands of DNA at the target site of genome, so as to achieve targeted knockout, knockin and gene modification of target site (Peng et al., 2019). The immune memory of CRISPR/Cas system is stored in the form of foreign genome interval sequence inserted into CRISPR array (Koonin et al., 2017). These spacer proteins, together with Cas proteins, serve as a monitoring system for the recognition and degradation of foreign nucleic acids. There are three stages in this process. The first stage, known as adaptive, immune, or spacer acquisition, involves the recognition and integration of foreign DNA (spacer) to CRISPR sites. The viral or plasmid DNA sequence in the spacer is called the primary spacer. Generally, there is a short conservative sequence near the original spacer, which is called the adjacent module of the original spacer (PAM). The second stage is the expression of system. A primary transcript (precrRNA) was transcribed from the CRISPR locus and processed into a small CRISPR RNAs (crRNA). In the final stage, known as interference or immunity, crRNAs, together with trans activated crRNA (tracrRNA), form ribonucleoprotein complexes with Cas proteins. The complex recognizes foreign DNA by base pairing and degrades it (Bhaya et al., 2011). The latest crispr-cas9 technology is based on the reconstruction of the immune system found in bacteria and archaea. Through RNA mediated Cas9 protein to recognize the target DNA sequence and cause DNA double strand breaks. Because of its simple and efficient characteristics, it has been widely used in the process of plant genetic improvement.

There are two essential components of genome editing using CRISPR/Cas system: DNA endonuclease and customizable single RNA (sgRNA) (Figure 1.). Cas9 has a double leaf structure, a large globular recognition leaf (REC) and a small nuclease leaf (NUC). There are 


\section{Macrothink

two nuclease domains, RuvC and $\mathrm{HNH}$, which each cut a specific DNA strand. SgRNA is a small non coding RNA, which is a fusion of crRNA and tracrRNA (Jinek et al., 2012). CRISPR/Cas system can be used to edit any sequence in any organism genome. The only necessary condition is that the target sequence must be adjacent to the PAM sequence. The 5'-NGG-3' recognition sequence of Streptococcus pyogenes Cas9 is PAM. However, there are other Cas proteins with different PAM sequences, such as Cpf1 (or Cas12) which recognize 5'- TTTN-3' or 5'- TTN-3' as PAM. In addition, new Cas9 variants (VQR, EQR and VRER) have been developed to identify alternative PAM, thus increasing the possibility of modifying any target sequence in the genome (Anders et al., 2016). The first report describing application of the CRISPR system to rice and wheat plants was published at 2013 (Shan et al., 2013). Since then, the system has been successfully used to edit the plant genome, and has been widely used in the genetic improvement process of rice and other major food crops.

An important feature of CRISPR/Cas9 system is that it can trans act on its target, so that it can isolate the mutation agents (CRISPR protein/ gene and sgRNA) from the sequence and modify them as required (Ricroch et al., 2017). In order to achieve this, it is necessary to obtain stable production of CRISPR/Cas mutant without CRISPR/Cas expression box in the final plant. This can be achieved by a variety of methods, such as genetic isolation, transient expression of CRISPR components, or transformation of ribonucleoprotein complexes (Pyott et al., 2016; Zhang et al., 2016; Liang et al., 2017). The simplest way to achieve this goal in rice is genetic isolation of transgenic plants in the next generation, which is the most commonly used method to obtain non transgenic plants. Of course, the transformation of ribonucleoprotein complex can also be realized in rice (Woo et al., 2015). Therefore, compared with other gene editing technologies, CRISPR/Cas gene editing system has the advantages of simple operation and high efficiency, which is widely used in plants. 

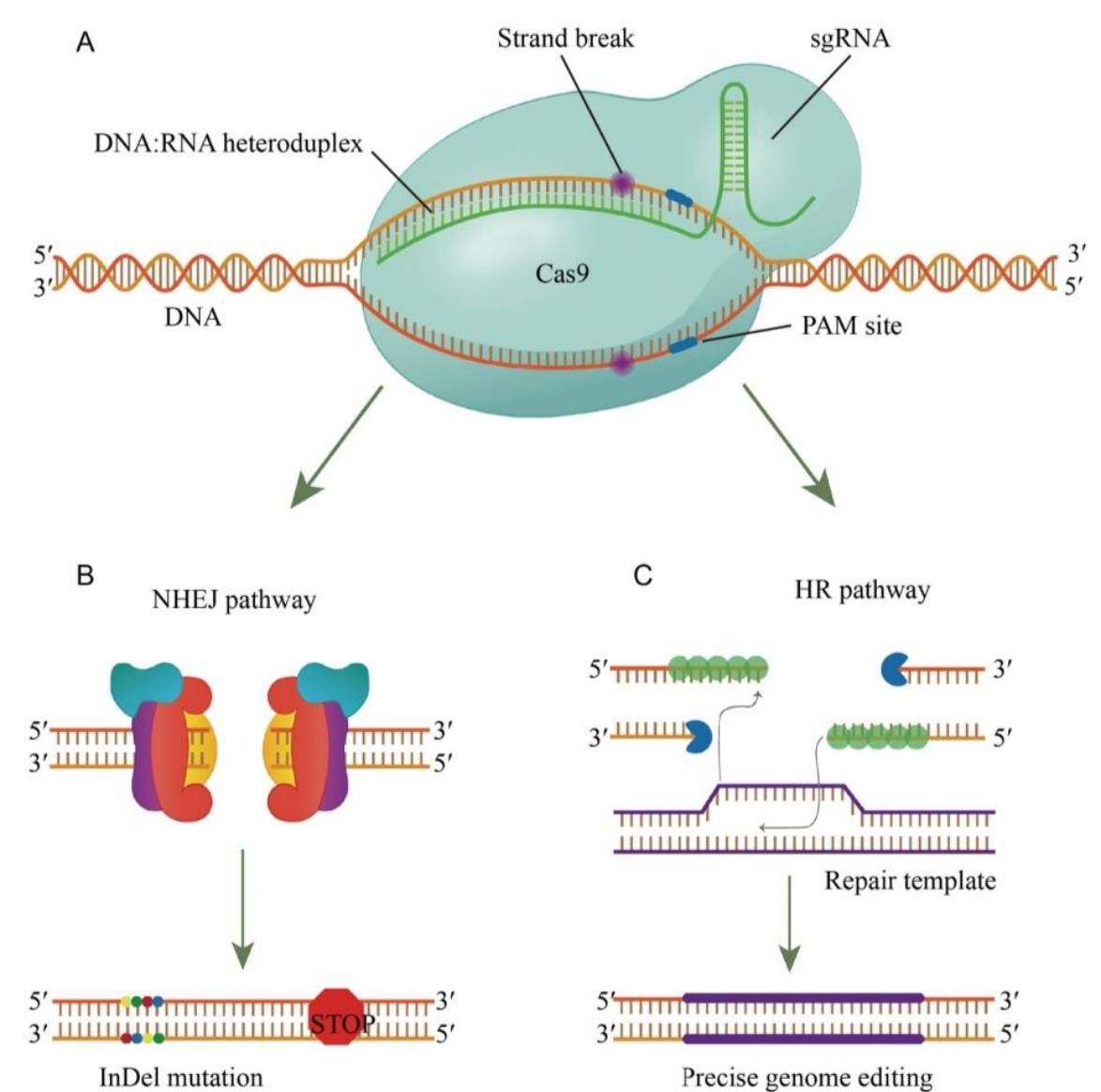

C HR pathway

Figure 1. CRISPR/Cas9 system components and pathways

A, Components required for genome editing using the CRISPR/Cas9 system: a DNA endonuclease (the most commonly used is the Cas9 protein from Streptococcus pyogenes) and a customizable single guide RNA (sgRNA). B, Non-homologous end-joining (NHEJ) repair pathway. C, Homologous recombination (HR) repair pathway. PAM, Protospacer adjacent motif (Fernando and Andrés, 2019).

\section{Advantages of CRISPR / Cas9 Technology}

At present, ZFN (zinc finger nuclease), TALEN (transcription activator- like effector nucleus) and CRISPR/Cas (the clustered regular interspace short palindromic) are the main genomic editing technologies repeat, all of which can precisely replace, insert and knock out plant genome, but ZFN and TALEN technology are relatively time-consuming and laborious (Liu, 2019). Compared with the two technologies, CRISPR/Cas9 technology has the advantages of high editing efficiency, flexibility, low cost and easy operation (Table 1), and has become the mainstream gene editing technology widely used at present (Liu, 2019). 
Table 1. Comparison of three gene editing techniques

\begin{tabular}{|c|c|c|c|c|}
\hline $\begin{array}{l}\text { Editing } \\
\text { technology }\end{array}$ & $\begin{array}{l}\text { Recognition } \\
\text { mode }\end{array}$ & Vector construction & Advantage & Insufficient \\
\hline ZFNs & $\begin{array}{l}\text { Specific } \\
\text { recognition } \\
\text { protein }\end{array}$ & $\begin{array}{l}\text { Complex, need to be } \\
\text { redesigned and } \\
\text { synthesized }\end{array}$ & $\begin{array}{l}\text { A ZFD can } \\
\text { specifically } \\
\text { recognize three } \\
\text { consecutive } \\
\text { nucleotides in } \\
\text { DNA strand }\end{array}$ & $\begin{array}{l}\text { Time consuming, } \\
\text { expensive, difficult } \\
\text { to operate, low } \\
\text { specificity and } \\
\text { serious Miss } \\
\text { problem }\end{array}$ \\
\hline TALENs & $\begin{array}{l}\text { Specific } \\
\text { recognition } \\
\text { protein }\end{array}$ & $\begin{array}{l}\text { Simple, redesigned } \\
\text { and synthesized }\end{array}$ & $\begin{array}{l}\text { High specificity, } \\
\text { low cost and high } \\
\text { efficiency }\end{array}$ & $\begin{array}{l}\text { Time consuming, } \\
\text { expensive, } \\
\text { cumbersome } \\
\text { carrier } \\
\text { construction, and } \\
\text { low editing } \\
\text { efficiency }\end{array}$ \\
\hline CRIDPR/Cas & $\begin{array}{l}\text { Homologous } \\
\text { recombination or } \\
\text { DNA repair }\end{array}$ & $\begin{array}{l}\text { Simple, cutting } \\
\text { target DNA } \\
\text { complementary and } \\
\text { non complementary } \\
\text { chains }\end{array}$ & $\begin{array}{l}\text { Editing efficiency } \\
\text { is high, flexible, } \\
\text { cheap, easy to } \\
\text { operate, and } \\
\text { exogenous genes } \\
\text { are easy to remove }\end{array}$ & $\begin{array}{l}\text { General specificity, } \\
\text { obvious Miss } \\
\text { effect, limited by } \\
\text { PAM recognition } \\
\text { site }\end{array}$ \\
\hline
\end{tabular}

One of the most attractive features of CRISPR/Cas9 system is its multiple editing ability, which leads to multiple gene mutations in the same transformation event, thus reducing the production time and cost of new plant varieties. This characteristic has been applied to the simultaneous mutation of the whole rice gene family. For example, eight sgRNAs targeting four members of mitogen activated protein kinase gene family were designed. Each pair targets two genomic sites within a single gene site, with an interval of 350-750 bp, so deletion sequences can be observed in the edited cells. A large number of sgRNAs were generated from a single CIS trans gene by using an endogenous tRNA processing system, which precisely cut both ends of the tRNA precursor. After protoplast transformation, the analysis of the target gene showed that the chromosome segments of the four target loci were effectively removed, and the mutation frequency was 4\%-20\%. When Agrobacterium tumefaciens transformed embryogenic callus, mutations occurred in 8 loci, among which 2 segments were missing (Xie et al., 2015). By using this system, we can obtain mutants with single, double and four genes simultaneously. The mutation efficiency of single mutant is $86 \%-100 \%$, that of double mutant is $67 \%-100 \%$, and that of four mutant is $86 \%$. The phenotype analysis of the mutants showed that there were severe dwarfing and sterile mpk 1 mutants and embryo development defects in the homozygous mpk1 seeds from heterozygous parents. On the contrary, heterozygous mpk6 mutant plants cannot produce homozygous mpk6 seeds at all (Minkenberg et al., 2017). Therefore, CRISPR/Cas9 system can play an important role in the research of rice multi gene mutation. 
Another important advantage of CRISPR/Cas9 in the application of major food crops is that in the first generation, transgenic plants can be obtained through the strategy of isolation. In rice, there are several examples of $\mathrm{T}_{1}$ generation plants without transgene mutation ( $\mathrm{Li}$ et al., 2016a; Wang et al., 2016b). Another way to obtain transgenic plants is to use ribonucleoprotein complex (Cas9 and sgRNAs) for DNA free genome editing. In rice protoplasts, about $20 \%$ mutation frequency was obtained by combining Cas9 with sgRNA targeting cytochrome P450 gene (Woo et al., 2015). Therefore, it promotes the application of CRISPR/Cas9 in major food crops and may be further commercialized.

At present, CRISPR/Cas9 is mainly used in plant genome editing, including gene function research and crop genetic improvement. The editing forms can be divided into four aspects: knockout of functional genes, insertion or replacement of genes (fragments), single base editing and gene expression regulation. In order to obtain $\mathrm{T}_{1}$ generation transgenic plants without exogenous genes, a new rice genetic transformation system has been developed. That is to say, using a pair of suicide genes in CRISPR/Cas9 system can effectively kill all pollen and embryos containing CRISPR/Cas produced by $\mathrm{T}_{0}$ plants. One is the gene for bacterial Barney's enzyme, which encodes a toxic protein that kills plant cells. The gene is controlled by REG2 promoter and expressed in early embryonic development. CRISPR/Cas9 system contains CMS2 gene, which encodes rice male gametophyte specific lethal protein under CaMV 35S promoter. In this way, $\mathrm{T}_{0}$ plants and CRISPR/Cas9 systems containing these expression boxes will produce toxic proteins that kill male gametophytes and embryos, and only produce non transgenic seeds. This structure is named CRISPR (TKC), a genetically modified killer (He et al., 2018). In order to test the system, a sgRNA targeting LAZY1 gene was designed, because the LAZY1 mutant has a large tillering angle and can easily identify the mutant individuals. After Agrobacterium tumefaciens transformed rice callus, $65 \mathrm{~T}_{0}$ plants were obtained, 29 of them were lazy type. No TKC or CRISPR/Cas system was found in 10 $\mathrm{T}_{0}$ plants. The target site of each $\mathrm{T}_{1}$ plant contains mutations. These plants are either homozygous or double allelic, showing $100 \%$ efficiency of eliminating the target gene (He et al., 2018). Therefore, CRISPR/Cas9 can effectively edit the target gene in plant genome and produce transgenic plants without carrying foreign gene sequence. CRISPR/Cas9 gene editing technology has developed rapidly in just a few years due to its advantages of simple operation, high editing efficiency, support for multi-target editing and various editing forms, and has been widely used in a variety of organisms, making an important contribution to the study of gene function and the inheritance and improvement of important traits of animals and plants. At present, CRISPR/Cas9 technology has also been applied to a variety of plants, including Arabidopsis ( $\mathrm{Li}$ et al., 2018a), rice (Macovei et al., 2018), wheat (Triticum aestivum) (Okada et al., 2019), maize (Lee et al., 2018), soybean (Glycine max) (Li et al., 2015), sorghum (Che et al., 2018), cotton (Gossypium hirsutum L.) (Li et al., 2018b; Qin et al., 2019), rapeseed (Brassica napus L.) (Braatz et al., 2017), barley (Hordeum vulgare L.) (Lawrenson, et al., 2015), Nicotiana benthamiana (Jansing et al., 2018), tomato (Solanum lycopersicum L.) (Ortigosa et al., 2019), potato (Solanum tuberosum) (Enciso-Rodriguez et al., 2019), sweet orange (Citrus sinensis L.) (Peng et al., 2017), cucumber (Cucumis sativus L.) (Chandrasekaran et al., 2016), wild cabbage (Brassica oleracea L.) (Lawrenson et al., 2015), wild legume (Lotus japonicus L.) (Wang et al., 2016a), lettuce (Lactuca sativa L.) 
(Woo et al., 2015), Medicago truncatula (Michno et al., 2015), Marchantia polymorpha (Sugano et al., 2014), tobacco (Nicotiana tabacum L.) (Baltes et al., 2014), Nicotiana attenuate (Woo et al., 2015), Petuniahybrida (Nicotiana attenuate) (Subburaj et al., 2016), grape (Vitis vinifera L.) (Wang et al., 2018), apple (Malus pumila) (Malnoy et al., 2016), tropical staplcassava (Manihot esculenta) (Odipio et al., 2017), watermelon (Citrullus lanatus) (Tian et al., 2017), and others. Especially in the process of genetic improvement of important characters in rice, a series of important progress has been made (Table 2).

Table 2. Examples of rice genetic improvement using CRISPR/Cas9

\begin{tabular}{|c|c|c|c|}
\hline Functional gene & Editing mode & Improved trait & Reference \\
\hline ERF922 & Knockout & Rice blast resistance & Wang et al., 2016c \\
\hline SWEET13 & Knockout & $\begin{array}{l}\text { Bacterial } \\
\text { resistance }\end{array}$ & Zhou et al., 2015 \\
\hline Nramp5 & Knockout & Low Cd accumulation & Tang et al., 2017 \\
\hline$S a F / S a M$ & Knockout & Hybrid compatibility & Xie et al., 2017 \\
\hline$S c$ & Knockout & Hybrid compatibility & Shen et al., 2017a \\
\hline SITPR/S1A4/S1A6 & Knockout & Hybrid compatibility & $\begin{array}{l}\text { Xie et al., 2017; Xie } \\
\text { et al., } 2019\end{array}$ \\
\hline$C S A$ & Knockout & $\begin{array}{l}\text { Reverse-photosensitive } \\
\text { sterility }\end{array}$ & Li et al., 2016b \\
\hline TMS5 & Knockout & $\begin{array}{l}\text { Thermo-sensitive } \\
\text { sterility }\end{array}$ & Zhou et al., 2016 \\
\hline$H d 2 / H d 4 / H d 5$ & Knockout & Early maturity & Li et al., 2017 \\
\hline$D E P 1 / E P 3$ & Knockout & Erect panicle & $\begin{array}{l}\text { Li et al., 2016b; } \\
\text { Shen et al., 2017b }\end{array}$ \\
\hline Gn1a & Knockout & Increasing grain number & $\begin{array}{l}\text { Li et al., 2016a; Shen } \\
\text { et al., 2017a }\end{array}$ \\
\hline$G S 3$ & Knockout & Increasing grain size & $\begin{array}{l}\text { Li et al., 2016b Shen } \\
\text { et al., } 2017 \mathrm{~b}\end{array}$ \\
\hline GW2/GW5/TGW6 & Knockout & Increasing grain weight & $\begin{array}{l}\text { Shen et al., } 2017 b \\
\text { Xu et al., } 2016\end{array}$ \\
\hline SBEIIb & Knockout & High amylose starch & Sun et al., 2017 \\
\hline Waxy & Knockout & Low amylose starch & $\begin{array}{l}\text { Ma et al., } 2015 \mathrm{a} \\
\text { Zhang et al., } 2018\end{array}$ \\
\hline$B A D H 2$ & Knockout & Enhancing fragrance & Shen et al., 2017b \\
\hline$A L S$ & Replace & Herbicide resistance & Sun et al., 2016 \\
\hline EPSPS & Replace & Herbicide resistance & Li et al., 2016b \\
\hline$A C C$ & Single-base editing & Herbicide resistance & Li et al., 2018c \\
\hline SLR1 & Single-base editing & Reducing plant height & Lu and Zhu, 2017 \\
\hline
\end{tabular}




\section{Application of CRISPR/Cas9 Technology in Rice Yield Genetic Improvement}

The yield of rice is mainly determined by the number of effective panicles, the number of grains per panicle and the weight of 1000 grains. Using gene editing technology, we have successfully improved the regulatory genes of rice yield traits, including GS3, DEPGS5, GW2, GN1 and TGW6 (Zhang et al., 2017). Li et al. (2018c) used CRISPR/Cas gene editing system to edit Gnla (OsCKX2), DEP1, GS3 and IAP1. These genes regulate grain number, ear structure, grain size and plant structure respectively (Li et al., 2016a). Using CRISPR/Cas9 system to edit $C C D 7$ gene, Butt et al. obtained a multi Tillering Mutant Rice (Butt et al., 2018). Li et al. (2017) used CRISPR/Cas9 mediated multi gene vector to edit three negative growth regulating genes $(H d 2, H d 4$ and $H d 5)$ at the same time, and obtained early maturing rice mutants. The storage characteristics of rice seeds are mainly regulated by lipoxygenase (LOXs). Three genes ( $L O X 1, L O X 2$ and $L O X 3)$ in $14 L O X$ gene families negatively regulate the storage properties of rice seeds. The application of targeted mutation LOX3 gene of TALENs improved the storage tolerance of rice seeds (Ma et al., 2015b). Therefore, using CRISPR/Cas9 technology to edit the negative regulatory genes of rice yield can improve the yield of rice.

A method combining pedigree analysis, whole genome sequencing and CRISPR/Cas9 technology can be used to identify genes that have important contribution to yield and other complex quantitative traits on a large scale (Huang et al., Huang 2018). For example, 30 parents and progenies of rice variety IR8 were sequenced, and 57 genes remained in all high-yielding lines were screened by Cas 9 or dCas 9 gene knockout or knockout for gene editing. The first exon of Gnla and GS3 and the third exon of DEPI and IPAI were selected as targets of sgRNAs, the mutation frequency of Gnla, DEPl, GS3 and IPAl were 42.5\%, $67.5 \%, 57.5 \%$ and $27.5 \%$ respectively. The plant height, panicle length and the number of flowers per panicle increased by about $90 \%$ compared with the control. The results showed that the plant height and ear length of depl mutant decreased by $20 \%$ compared with the control, but the number of flowers per ear increased by $50 \%$ compared with the control. GS3 mutant showed larger grain size and longer awn on shell. Finally, mutations in IPAI produce three phenotypes based on the nature of the mutations (Li et al., 2016b). SgRNA was designed to mutate miR156 target site. If the mutation does not cause frame shift or change miR156 target, the phenotype is the same as wild type. If the mutation changed the target position of miR156, but did not produce the frame shift of protein, then the mutant plant has 2-4 tillers, less than the wild type 7-10 tillers, but the plant height, flower number and ear length were increased than the wild type.

Rice yield is a complex quantitative trait, which is affected by many factors, including some important agronomic traits and QTLs genes. CRISPR/Cas9 mediated multiple genome editing system is one of the most attractive features of the technology, especially in the editing of QTLs to improve rice yield. Xu et al. (2016) edited three QTLs genes related to grain weight, GW2, GW5 and TGW6. They found that the functional characteristics of these three genes are good, and the mutation of any of them will lead to a significant increase in grain weight. They used CRISPR/Cas9 system to mutate three grain weight related genes GW2, GW5 and TGW6 at the same time, and found that rice mutants with 1000 grain weight 
increased by $29.3 \%$ compared with wild type. In addition, GW5, TGW6 and GW2 mutants had larger grain size than wild type. The length, width and 1000 grain weight of double mutants increased by $12 \%, 8 \%$ and $13 \%$, respectively. The grain length, grain width and 1000 grain weight of the three mutants increased by about $25 \%, 20 \%$ and $28 \%$, respectively. Therefore, CRISPR/Cas9 mediated multiple genome editing system is suitable for the rapid generation and aggregation of beneficial alleles in rice, which is conducive to rice yield.

Using CRISPR/Cas technology to knock out the precise region of the target gene may also improve the yield of rice. Compared with wild type, the deletion of 625 bp in DEP1 gene gave dense erect panicles higher grain number and lower plant height (Huang et al., 2009). With this in mind, Wang et al. (2017) designed four sgRNAs (S1-S4) to achieve the same deletion in indica rice. These four sgRNAs are distributed in four different structures: S1/S4, $\mathrm{S} 1 / \mathrm{S} 3, \mathrm{~S} 2 / \mathrm{S} 4$ and $\mathrm{S} 1 / \mathrm{S} 2 / \mathrm{S} 3 / \mathrm{S} 4$. In $96 \mathrm{~T}_{0}$ events of each structure, the deletion frequency of $430 \mathrm{bp}$ target is as high as $21 \%$, and that of $10 \mathrm{~kb}$ target is as high as $9 \%$. depl mutants produced by CRISPR/Cas showed ideal phenotypes (dense erect panicles and reduced plant height). Hence, high yield of rice can be achieved by using CRISPR/Cas9 technology to knock out the specific location of the target gene.

\section{Application of CRISPR/Cas9 Technology in Genetic Improvement of Rice Quality}

An important goal of rice genetic improvement is to breed new rice varieties with high quality, high yield and high resistance. Generally, rice quality includes appearance quality, nutrition quality, processing quality and cooking and eating quality. Amylose content is the most important index of rice quality for cooking and eating quality. Seeds with high levels of amylose are good sources of resistant starch, a special type of starch that is not digested in the stomach or small intestine but is passed directly to the large intestine. Resistant starch helps improve human health and reduce the risk of non-communicable diseases (Regina et al., 2006). The content of amylose and resistant starch in rice could be increased by changing the branching enzyme (SBEs) of starch. The CRISPR/Cas technology was used to edit the $S B E I I b$ gene expressed in rice grains. After the transformation of rice callus mediated by agrobacterium-mediated, 22 of the 30 transgenic plants mutated in the target region, producing heterozygous, double allelic and homozygous mutants at frequencies of $6.7 \%$, $36.6 \%$ and $26.7 \%$, respectively (Sun et al., 2017). No off-target effect was detected in the predicted sites. After the isolation of the non-transgenic mutant lines, the content of amylose and resistant starch in sbeII mutant were increased significantly.

The amylose content in rice seeds is mainly controlled by the Waxy dominant gene, by using the CRISPR/Cas9 technique, we can obtain the mutant of Waxy function deficiency. Through the design of a sgRNA targeting the first exon of Waxy gene, in the callus of two rice varieties (Xiushui 134 和 Wuyunjing 7), $\mathrm{T}_{0}$ transformant had high mutagenesis efficiency (82\% 87\%) with the help of soil agrobacteria-mediated genetic transformation, and about $4 \%-15 \%$ of the mutants were homozygous (Zhang et al., 2018). Interestingly, the analysis of agronomic traits of $\mathrm{T}_{1}$-generation plants showed that there were no significant differences in plant height, panicle grain number, panicle number per plant, plot yield, grain width, grain length and 1000-grain weight between the wild type and the mutant. But the amylose content of the 
Waxy mutant was significantly lower than that of the wild type rice (Zhang et al., 2018). By constructing the expression of CRISPR/Cas9 with pGK03-Wx-gRNA (target 1 and 2 in exon 1 and exon 2 of $W x$ gene, respectively), the engineering bacteria EHA105 was used to genetically transform the super rice Chujing 27, and 9 independent $\mathrm{T}_{0}$-generation transformed lines were screened by hygromycin, with 5 lines at target 1 (L1 L5) with mutation frequency of $100 \%$ and 4 lines at target 2 (L6 L9) with mutation frequency of 75\%. Compared with the wild type, the expression of RNA level $W x$ gene in mutant lines significantly decreased, and the amylose content in rice significantly decreased (Wang, 2018). Waxy strains of indica rice and japonica rice were obtained by using CRISPR/Cas9 technology to knock out the gene Waxy that controlled amylose content (Ma et al., 2015b). This provides important information for the cultivation of new glutinous varieties of indica rice and japonica rice.

By using CRISPR/Cas9 technology, site-directed editing of PUL gene regulating defunct enzyme in rice was carried out, and the allelic variation of $P U L$ with important breeding value was obtained. By knockout of $O s P U L$, it was found that the amylose content of $\mathrm{T}_{0}-18$ decreased by $18.70 \%$ and the protein content increased by $22.02 \%$ (Feng et al., 2019). Further analysis of mutants revealed that the decrease of $G W 8$ expression in the mutants weakened its inhibition on $G L 7$, which increased the expression of GL7 and led to an increase in grain length. By constructing the knockout expression vector of FAD2-1 gene by CRISPR/Cas9, 6 independent mutant lines were produced by means of agrobacterium-mediated genetic transformation of rice callus (Feng et al., 2019). After the offspring were evaluated to confirm the mutation, the fatty acid spectrum of $\mathrm{T}_{2}$ series was analyzed (Abe et al., 2018). It was found that in the fad2-1 homozygous mutant, the oleic acid content increased to more than twice that of the wild type, and no linoleic acid was detected. Therefore, the knockout of FAD2-1 gene by CRISPR/Cas9 can produce an increase in oleic acid content in rice seeds.

The field of fragrant rice, favored by the majority of consumers, has a broad market prospect. The CRISPR/Cas9 technology was used to edit the aroma gene OSBADH2 of rice, and the mutant of fragrant rice (Shao et al., 2015). Shao people through the CRISPR/CAS9 technology such as high energy of the fragrance of flowers in 11 Badh2 gene editing, obtained in the derivative of the $\mathrm{T}_{1}$ generation of a carrier to cut out the skeleton and insert a bases on exon $1 \mathrm{~T}$ of mutant materials, the material in the Badh2 significantly lower in the RNA expression level, determination of flavoring substances in results showed that the mutant materials significantly increased (Shao et al., 2017). In addition, the yield and cooking taste quality of wild type and $\mathrm{T}_{2}$ type rice were examined and analyzed, and it was found that there was no significant difference between the two groups except tiller number and seed setting rate $(P<0.05)$. The scent japonica rice varieties farmers 425 as test material, build the two CRISPR/Cas9 Badh2 gene knockout carrier on fixed-point editor, the first carrier (pYLCRISPR/ Cas9-B1-gRNA) of two targets located in exon 2 and 3, respectively the second carrier (pYLCRISPR/ Cas9-B2-gRNA) on the two targets are in exon 2, succeeded $\mathrm{T}_{0}$ homozygous plants, and the $\mathrm{T}_{-} \mathrm{T}_{1}$ generation plants DNA element detection, a total of 8 homozygous mutant strains with different mutation types and without transgenic ingredients were obtained (Sun et al., 2019). At the same time, the rice seeds of these 8 homozygous 
mutant lines were tested for aroma. The results showed that the 8 Badh2 lines all had different degree of aroma, and the 3 lines edited by pYLCRISPR/ Cas9-B1-gRNA were more fragrant.

Using the CRISPR/Cas9 editing technology, in view of water rice protein GluA gene exon 4 of regional design sequence specific gene specificity knockout, gumming point are successfully obtained two mutant genes GluA3 materials, these two mutant materials GluA3 gene expression levels were significantly lower in RNA, protein translation early termination (Zhou et al., 2019). Among them, the molecular weight of GluA3 protein of $M_{1}$ mutants changed from $56.03 \mathrm{ku}$ to $51.13 \mathrm{ku}$, while that of $\mathrm{M}_{2}$ mutants changed to $51.94 \mathrm{ku}$, leading to the functional change of GluA3 protein in mutants, and the content of GluA3 in rice showed a downward trend. Therefore, the use of CRISPR/Cas9 technology for precise gene editing of important functional genes controlling rice quality traits can achieve targeted functional gene knockout, fixed-point insertion or replacement of genes (fragments), single-base editing and gene expression regulation, and thus achieve genetic improvement of rice quality traits.

\section{Problems and Prospects of CRISPR/Cas9 Technology}

CRISPR/Cas9 technology has been widely used in many plants because of its advantages such as simple operation, high editing efficiency, support for multi-target editing and various editing forms. It has made an important contribution to the genetic improvement of important characters of rice and other major food crops. Until now, CRISPR/Cas9 system is considered as the best choice of transgenic technology in plant species, but there are still some limitations in practical application (Figure 2). In recent years, in order to improve the editing efficiency and reliability of CRISPR system, a lot of research on the improvement of the system, and new CRISPR/CAS variants have emerged. For example, spCas9-NG, base editing, xCas9, etc. (Manghwar et al., 2019). The key problems and advantages of CRISPR/Cas9 technology are as follows:

(1) CRISPR/Cas9 system is large in size and low in editing efficiency, so it is not suitable to be packaged as a virus carrier and transported to somatic tissues. Therefore, CRISPR/Cas9 system is required to have high editing efficiency (Hakim et al., 2019).

(2) SpCas9 needs a 5'-NGG-3' PAM next to a 20-nt DNA target sequence, in which it only recognizes NGG PAM sites, which limits its effectiveness compared with the new CRISPR/Cas variant. However, the xCas9 variant has higher targeting efficiency, higher DNA specificity, lower Miss activity and extensive PAM compatibility (e.g., with NG, GAT and GAA) (Hakim et al., 2019).

(3) CRISPR/Cas9 can introduce multiple random non targeted mutations into the genome (Zhang et al., 2015). However, the new CRISPR/Cas variant improves the editing efficiency of the target base in the sequence of interest by identifying different PAMs (Hua et al., 2019). CRISPR/Cas9 introduced mutations at nonspecific sites with similar but not identical homology to the target site.

(4) CRISPR/Cas9 needs an Agrobacterium mediated transformation system to produce the mutant, which is not only costly, but also time-consuming. In the future, it is possible to 


\section{NI Macrothink}

Journal of Biology and Life Science

ISSN 2157-6076

2020, Vol. 11, No. 2

further improve the editing efficiency of CRISPR system by using genome editing system without tissue culture.

(5) The main problem of industrialization of crops produced by CRISPR/Cas9 technology is the strict supervision and control of genetically modified crops in various countries.

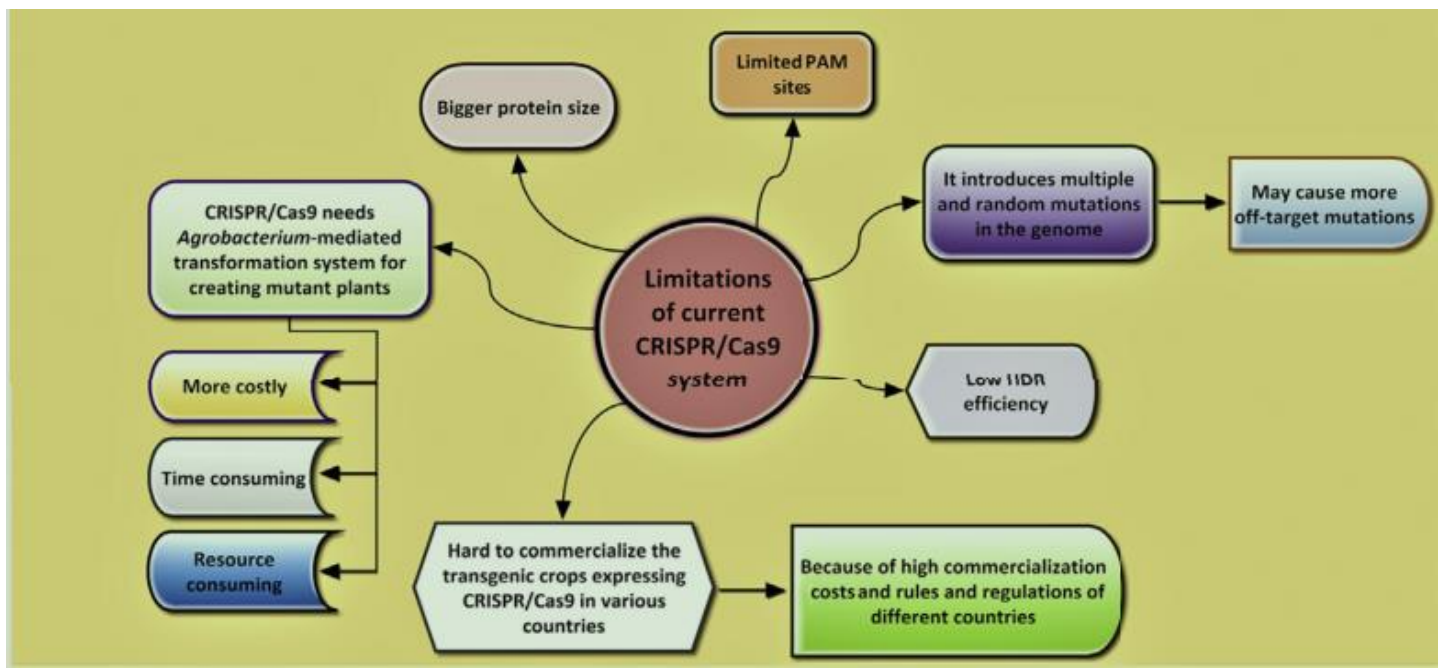

Figure 2. Limitations of current CRISPR/Cas9 system

Abbreviation: Cas9, CRISPR-associated nuclease 9; CRISPR, clustered regularly interspaced short palindromic repeat; HDR, homology-directed repair; PAM, protospacer adjacent motif (Manghwar et al., 2019).

Since CRISPR/Cas genome editing system was first implemented in 2013, with the continuous progress of technology and large-scale sequencing technology, it is possible to create new rice varieties with specific site directed mutations without non targeted mutations (Romero et al., 2019). However, the application of genome editing is still insufficient, which restricts the further application of CRISPR/Cas9 in rice and other crops. Therefore, optimizing gene editing technology can further promote the development and application of crop genetic improvement (Chen et al., 2019). For example, to reduce the requirements of CRISPR genome editing system for PAM sequence; to improve the efficiency of gene replacement editing and reduce the Miss effect; to not directly obtain genome edited rice and other crops in early farmland (Chen et al., 2019). In addition, whether gene editing crops belong to genetically modified organisms has not been clearly determined in the world, and its regulatory standards are controversial (Liu, 2019). Therefore, it is necessary to strengthen the supervision and regulation construction of gene editing crops. It is necessary to organize the scientific community, managers, industry and other communities to discuss, formulate practical laws and regulations, strictly monitor their application scope and degree, and develop the gene editing and breeding technology in accordance with the safety standards.

Genomic editing technology can create genetically modified crops. CRISPR/Cas9 and related genomic editing tools have indeed brought revolutionary changes in rice improvement, which is of great significance to meet and ensure people's demand for high quality and yield of rice 
in the future. However, there are still many technical difficulties in CRISPR based plant genome editing technology system that have not been solved yet. To develop a more efficient and accurate gene editing system and optimize mutation detection technology are still the direction of future efforts.

\section{Acknowledgments}

This work was financially supported by National Natural Science Foundation of China (U1604110, U1404319, 31600992, 31801332), Key Project of Science and Technology in Henan Province (192102110119, 182102110442), National Key R\&D Program Projects (2016YFD0100101-10), The Training Plan of Young Backbone Teachers in Colleges and universities of Henan Province (2019GGJS162), Postgraduate Education Reform Project of Henan Province (2019SJGLX088Y), Key Scientific Research Projects of Universities in Henan Province (19A180030), Nanhu Scholars Program for Young Scholars of XYNU (2016054), Innovative Training Program for University Students in Henan Province (201910477004).

\section{References}

Abe, K., Araki, E., Suzuki, Y., Toki, S., \& Saika, S. (2018). Production of high oleic/low linoleic rice by genome editing. Plant Physiology and Biochemistry, 131, 58-62. https://doi.org/10.1016/j.plaphy.2018.04.033

Anders, C., Bargsten, K., \& Jinek, M. (2016). Structural plasticity of PAM recognition by engineered variants of the RNA-guided endonuclease Cas9. Mol Cell, 61(6), 895-902. https://doi.org/10.1016/j.molcel.2016.02.020

Baltes, N. J., Gil-Humanes, J., Cermak, T., Atkins, P. A., \& Voytas, D. F. (2014). DNA Replicons for plant genome engineering. The Plant Cell, 26(1), 151-163. https://doi.org/10.1105/tpc.113.119792

Bhaya, D., Davison, M., \& Barrangou, R. (2011). CRISPR-Cas systems in bacteria and archaea: Versatile small RNAs for adaptive defense and regulation. Annual Review of Genetics, 45(1), 273-297. https://doi.org/10.1146/annurev-genet-110410-132430

Braatz, J., Harloff, H. J., Mascher, M., Stein,N., Himmelbach, A., \& Jung, C. (2017). CRISPR-Cas9 targeted mutagenesis leads to simultaneous modification of different homoeologous gene copies in polyploid oilseed rape (Brassica napus). Plant Physioogyl, 174(2), 935- 942. https://doi.org/10.1104/pp.17.00426

Chandrasekaran, J., Brumin, M., Wolf, D., Leibman, D., Klap, C., Pearlsman, M., ... Gal-on, A. A. (2016). Development of broad virus resistance in non-transgenic cucumber using CRISPR/Cas9 technology. Molecular Plant Pathology, 17(7), 1140-1153. https://doi.org/10.1111/mpp.12375

Che, P., Anand, A., Wu, E., \& Sander, J. D. (2018). Developing a flexible, high-efficiency Agrobacterium-mediated sorghum transformation system with broad application. Plant Biotechnology Journal, 16(7), 1388-1395. https://doi.org/10.1111/pbi.12879 
Chen, K. L., Wang, Y. P., Zhang, H., \& Gao, C. (2019). CRISPR/Cas genome editing and precision plant breeding in agriculture. Annual Review of Plant Biology, 70, 667-697. https://doi.org/10.1146/annurev-arplant-050718-100049

Doudna, J. A., \& Charpentier, E. (2014). Genome editing. The new frontier of genome engineering with CRISPR-Cas9. Science, 346(6213), 1258096. https://doi.org/10.1126/science.1258096

Enciso-Rodriguez, F., Manrique-Carpintero, N. C., Nadakuduti, S. S., Buell, C. R., Zarka, D., \& Douches, D. (2019). Overcoming self-incompatibility in diploid potato using CRISPRCas9. Frontiers in Plant Science, 10, 376. https://doi.org/10.3389/fpls.2019.00376

Feng, B. B., Wei, X. J., Jiao, G. A., Hun, S. K., Wu, Y. W., Xie, L. H., ... Tang, S. Q. (2019). CRISPR/Cas9 editing starch synthesis gene PUL. China Rice, 25(5), 99-104.

Fernando Matías, R., \& Andrés, G. A. (2019). CRISPR/Cas9: development and application in rice breeding. Rice Science, 26(5), 265-281. https://doi.org/10.1016/j.rsci.2019.08.001

He, W. D. (2014). Challenges and countermeasures of food security in China. Southern Agriculture, 35(8), 23-25.

He, Y. B., Zhu, M., Wang, L. H., Wu, J. H., Wang, Q. Y., Wang, R. C., \& Zhao, Y. D. (2018). Programmed self-elimination of the CRISPR/Cas9 construct greatly accelerates the isolation of edited and transgene-free rice plants. Molecular Plant, 11(9), 1210-1213. https://doi.org/10.1016/j.molp.2018.05.005

Hermans, P. W., van Soolingen, D., Bik, E. M., de Haas, P. E., Dale, J. W., \& van Embden, J. D. (1991). Insertion element IS987 from Mycobacterium bovis BCG is located in a hot-spot integration region for insertion elements in Mycobacterium tuberculosis complex strains. Infect Immun, 59(8), 2695-2705. https://doi.org/10.1128/IAI.59.8.2695-2705.1991

Hua, K., Tao, X. P., Han, P. J., Wang, R., \& Zhu, J. K. (2019). Genome engineering in rice using Cas9 variants that recognize ng pam sequences. Molecular Plant, 7(12), 1003-1014. https://doi.org/10.1016/j.molp.2019.03.009

Huang, J., Li, J., Zhou, J., Wang, L., Yang, S., Hurst, L. D., Li, W. H., \& Tian, D. (2018). Identifying a large number of high-yield genes in rice by pedigree analysis, whole-genome sequencing, and CRISPR-Cas9 gene knockout. PNAS, 115(32), E7559-E7767. https://doi.org/10.1073/pnas.1806110115

Huang, X, Z., Qian, Q., Liu, Z. B., Sun, H. Y., He, S. Y., Luo, D., ... Fu, X. D. (2009). Natural variation at the DEP1 locus enhances grain yield in rice. Nature Genetcs, 41(4), 494-497. https://doi.org/10.1038/ng.352

Ishino, Y., Shinagawa, H., Makino, K., Amemura, M., \& Nakata, A. (1987). Nucleotide sequence of the iap gene, responsible for alkaline phosphatase isozyme conversion in Escherichia coli, and identification of the gene product. Journal of Bacteriology, 169(12), 5429-5433. https://doi.org/10.1128/JB.169.12.5429-5433.1987 
Jansing, J., Sack, M., Augustine, S. M., Fischer, R., \& Bortesi, L. (2018). CRISPR/Cas9-mediated knockout of six glycosyltransferase genes in Nicotiana benthamiana for the production of recombinant proteins lacking $\beta-1,2$ - xylose and core $\alpha-1,3$ - fucose. Plant Biotechnology Journal, 17(2), 350-361. https://doi.org/10.1111/pbi.12981

Jinek, M., Chylinski, K., Fonfara, I., Hauer, M., Doudna, J. A., \& Charpentier, E. (2012). A programmable dual-RNA: Guided DNA endonuclease in adaptive bacterial immunity. Science, 337(6096), 816-821. https://doi.org/10.1126/science.1225829

Koonin, E. V., Makarova, K. S., \& Zhang, F. (2017). Diversity, classification and evolution of CRISPR-Cas systems. Current Opinion in Microbiology, 37, 67-78. https://doi.org/10.1016/j.mib.2017.05.008

Krappmann, S. (2017). CRISPR-Cas9, the new kid on the block of fungal molecular biology. Medical Mycology, 55(1), 16-23. https://doi.org/10.1093/mmy/myw097

Kusano, M., Yang, Z., Okazaki, Y., Nakabayashi, R., Fukushima, A., \& Saito, K. (2015). Using metabolo mic approaches to explore chemical diversity in rice. Molecular Plant, 8(1), 58-67. https://doi.org/10.1016/j.molp.2014.11.010

Lawrenson, T., Shorinola, O., Stacey, N., Li, C., Stergaard, L., Patron, N., Uauy, C., \& Harwood, W. (2015). Induction of targeted, heritable mutations in barley and Brassica oleracea using RNA-guided Cas9 nuclease. Genome Biology, 16(1), 258. https://doi.org/10.1186/s13059-015-0826-7

Lee, K., Zhang, Y. X., Kleinstiver, B. P., Guo, J. A., Aryee, M. J., Miller, J., ... Wang, K. (2018). Activities and specificities of CRISPR/Cas9 and Cas12a nucleases for targeted mutagenesis in maize. Plant Biotechnology Journal, 17(2), 362-372. https://doi.org/10.1111/pbi.12982

Li, A., Jia, S., Yobi, A., Ge, Z., Sato, S. J., Zhang, C., ... Holding, D. R. (2018a). Editing of an alpha-kafirin gene family increases, digestibility and protein quality in Sorghum. Plant Physiology, 177(4), 1425-1438. https://doi.org/10.1104/pp.18.00200

Li, B., Cui, G., Shen, G., Zhan, Z., Huang, L., Chen, J., \& Qi, X. (2017). Targeted mutagenesis in the medicinal plant Salvia miltiorrhiza. Scientific Reports, 7, 43320. https://doi.org/10.1038/srep43320

Li, C., Chen, C., Chen, H., Wang, S., Chen, X., \& Cui, Y. (2018b). Verification of DNA motifs in Arabidopsis using CRISPR/Cas9-mediated mutagenesis. Plant Biotechnology Journal, 16(8), 1446-1451. https://doi.org/10.1111/pbi.12886

Li, J., Manghwar, H., Sun, L., Wang, P., Wang, G., Zhang, J., Liu, H., ... Zhang, X. (2018c) Whole genome sequencing reveals rare off-target mutations and considerable inherent genetic or/and somaclonal variations in CRISPR/Cas9-edited cotton plants. Plant Biotechnology Journal, 17(5), 858-868. https://doi.org/10.1111/pbi.13020

Li, J., Meng, X. B., Zong, Y., Chen, K., Zhang, H., Liu, J., ... Gao, C. (2016a). Gene replacements and insertions in rice by intron targeting using CRISPR-Cas9. Nature Plants, 
2(2), 16139. https://doi.org/10.1038/nplants.2016.139

Li, M. R., Li, X. X., Zhou, Z. J., Wu, P. Z., Fang, M. C., Pan, X. P., ... Li, H. Q. (2016b). Reassessment of the four yield-related genes Gn1a, DEP1, GS3, and IPA1 in rice using a CRISPR/Cas9 system. Frontiers in Plant Science, 377. https://doi.org/10.3389/fpls.2016.00377

Li, Z., Liu, Z. B., Xing, A. Q., Moon, B. P., Koellhoffer, J. P., Huang, L., ... Cigan, A. M. (2015). Cas9-guide RNA directed genome editing in soybean. Plant Physiology, 169(2), 960-970. https://doi.org/10.1104/pp.15.00783

Liang, Z., Chen, K., Li, T., Zhang, Y., Wang, Y., Zhao, Q., Liu, J., ... Gao, C. (2017). Efficient DNA-free genome editing of bread wheat using CRISPR/Cas9 ribonucleoprotein complexes. Nature Communications, 8(18), 14261. https://doi.org/10.1038/ncomms14261

Liu, Z. Q. (2019). CRISPR/Cas9 technology and its application in crop genetic breeding. Crop Research, 33(3), 240-245.

Lu, Y., \& Zhu, J. (2017). Precise editing of a target base in the rice genome using a modified CRISPR/Cas9 system. Molecular Plant, 10(3), 523-525. https://doi.org/10.1016/j.molp.2016.11.013

Ma, X., Zhang, Q., Zhu Q., Liu, W., Chen, Y., Qiu, R., ... Liu, Y. G. (2015a). A robust CRISPR/Cas9 system for convenient, high-efficiency multiplex genome editing in monocot and dicot plants. Molecular Plant, 8(8), 1274-1284. https://doi.org/10.1016/j.molp.2015.04.007

Ma, L., Zhu, F., Li, Z., Zhang, J., Li, X., Dong, J., \& Wang, T. (2015b). TALEN-based mutagenesis of lipoxygenase LOX3 enhances the storage tolerance of rice (Oryza sativa) seeds. PLoS One, 10(12), e0143877. https://doi.org/10.1371/journal.pone.0143877

Macovei, A., Sevilla, N. R., Cantos, C., Jonson, G. B., Slamet-Loedin, I., Čermák, T., ... Chadha-Mohanty, P. (2018). Novel alleles of rice eIF4G generated by CRISPR/Cas9-targeted mutagenesis confer resistance to rice tungro spherical virus. Plant Biotechnology Journal, 16(11), 1918-1927. https://doi.org/10.1111/pbi.12927

Malnoy, M., Viola, R., Jung, M. H., Koo, O. J., Kim, S., Kim, J. S., Velasco, R., \& Nagamangala Kanchiswamy, C. (2016). DNA-free genetically edited grapevine and apple protoplast using CRISPR/Cas9 ribonucleoproteins. Frontiers in Plant Science, 7(20), 1904. https://doi.org/10.3389/fpls.2016.01904

Manghwar, H., Lindsey, K., Zhang, X. L., \& Jing, S. X. (2019). CRISPR/Cas system, recent advances and future prospects for genome editing. Trends in Plant Science, 12(24), 1102-1125. https://doi.org/10.1016/j.tplants.2019.09.006

Michno, J. M., Wang, X. B., Liu, J. Q., Curtin, S. J., Kono, T. J., \& Stupar, R. M. (2015). CRISPR/Cas mutagenesis of soybean and Medicago truncatula using a new web-tool and a modified Cas9 enzyme. GM Crops and Food, 6(4), 243-252. https://doi.org/10.1080/21645698.2015.1106063 
Minkenberg, B., Xie, K. B., \& Yang, Y. N. (2017). Discovery of rice essential genes by characterizing a CRISPR-edited mutation of closely related rice MAP kinase genes. Plant Journal, 89(3), 636-648. https://doi.org/10.1111/tpj.13399

Nakata, A., Amemura, M., \& Makino, K. (1989). Unusual nucleotide arrangement with Reportseated sequences in the Escherichia coli K-12 chromosome. Journal of Bacteriology, 171(6), 3553-3556. https://doi.org/10.1128/JB.171.6.3553-3556.1989

Odipio, J., Alicai, T., Inelbrecht, I. L., Nusinow, D. A., Bart, R., \& Taylor, N. J. (2017). Efficient CRISPR/Cas9 genome editing of phytoene desaturase in cassava. Frontiers in Plant Science, 8, 1780. https://doi.org/10.3389/fpls.2017.01780

Okada, A., Arndell, T., Borisjuk, N., Sharma, N., Watson-Haigh, N. S., Tucker, E. J., ... Whitford, R. (2019). CRISPR/Cas9-mediated knockout of Ms1 enables the rapid generation of male-sterile hexaploid wheat lines for use in hybrid seed production. Plant Biotechnology Journal, 17(10), 1905-1913. https://doi.org/10.1111/pbi.13106

Ortigosa, A., Gimenez-Ibanez, S., Leonhardt, N., Solano, R. (2019). Design of a bacterial speck resistant tomato by CRISPR/Cas9-mediated editing of SIJAZ2. Plant Biotechnology Journal, 17(3), 665-673. https://doi.org/10.1111/pbi.13006

Peng, A., Chen, S. C., Lei, T. G., Xu, L., He, Y., Wu, L., Yao, L., \& Zou, X. (2017). Engineering canker-resistant plants through CRISPR/Cas9-targeted editing of the susceptibility gene CSLOB1 promoter in citrus. Plant Biotechnology Journal, 15(12), 1509-1519. https://doi.org/10.1111/pbi.12733

Peng, B., Li, J., Kong, D., He, L., Li, M., Nassirou, T. Y., ... Yuan, H. (2019). Genetic improvement of grain quality promoted by high and new technology in rice. Journal of Agricultural Science, 11(1), 81-94. https://doi.org/10.5539/jas.v11n1p81

Peng, B., Sun, Y. F., Li, Q. R., Li, D., Pang, R. H., Zhou, Q. T., ... Song, S. Z. (2016). Progress in genetic study of Chalkiness in Rice. Journal of Xinyang Normal University (NATURAL SCIENCE EDITION), 29(2), 304-312.

Pyott, D. E., Sheehan, E., \& Molnar, A. (2016). Engineering of CRISPR/Cas9-mediated potyvirus resistance in transgene-free Arabidopsis plants. Molecular Plant Pathology, 17(8), 1276-1288. https://doi.org/10.1111/mpp.12417

Qin, L., Li, J. Y., Wang, Q. Q., Xu, Z., Sun, L., Alariqi, M., ... Jin, S. (2019). High efficient and precise base editing of $\mathrm{C} \cdot \mathrm{G}$ to $\mathrm{T} \cdot \mathrm{A}$ in the allotetraploid cotton (Gossypium hirsutum) genome using a modified CRISPR/Cas9 system. Plant Biotechnology Journal, 18(1), 1-12. https://doi.org/10.1111/pbi.13168

Regina, A., Bird, A., Topping, D., Bowden, S., Freeman, J., Barsby, T., ... Morell, M. (2006). High-amylose wheat generated by RNA interference improves indices of large-bowel health in rats. Proceedings of the National Academy of Scientificences of the United States of America, 103(10), 3546-3551. https://doi.org/10.1073/pnas.0510737103

Romero, F. M., \& Gatica-Arias, A. (2019). CRISPR/Cas9, development and application in 
rice breeding. Rice Science, 26(5), 265-281.

Shan, Q. W., Wang, Y. P., Li, J., Zhang, Y., Chen, K. L., Liang, Z., ... Gao, C. X. (2013). Targeted genome modification of crop plants using a CRISPR-Cas system. Nature Biotechnolagy, 31(8), 686-688. https://doi.org/10.1038/nbt.2650

Shan, Q., Zhang, Y., Chen, K., Zhang, K., \& Gao, C. (2015). Creation of fragrant rice by targeted knockout of the OsBADH2 gene using TALEN technology. Plant Biotechnology Journal, 13(6), 791-800. https://doi.org/10.1111/pbi.12312

Shao, G. N., Xie, L. H., Jiao, G. A., Wei, X. J., Sheng, Z. H., Tang, S. Q., \& Hu, P. S. (2017). Editing rice flavor gene Badh2 by CRISPR/CAS9. Rice Science in China, 31(2), 216-222.

Shen, L., Hua, Y., Fu, Y., Li, J., Liu, Q., Jiao, X., ... Wang, K. (2017a). Rapid generation of genetic diversity by multiplex CRISPR/Cas9 genome editing in rice. Sciences China Life Sciences, 60(5), 506-515. https://doi.org/10.1007/s11427-017-9008-8

Shen, R., Wang, L., Liu, X., Wu, J., Jin, W., Zhao, X., ... Liu, Y. G. (2017b). Genomic structural variation-mediated allelic suppression causes hybrid male sterility in rice. Nature Communications, 8(1), 1310. https://doi.org/10.1038/s41467-017-01400-y

Subburaj, S., Chung, S. J., Lee, C., Ryu, S. M., Kim, D. H., Kim, J. S., ... Lee, G. J. (2016). Site-directed mutagenesis in Petunia $\times$ hybrida protoplast system using direct delivery of purified recombinant Cas9 ribonucleoproteins. Plant Cell Reports, 35(7), 1535-1544. https://doi.org/10.1007/s00299-016-1937-7

Sugano, S. S., Shirakawa, M., Takagi, J., Matsuda, Y., Shimada, Y., Hara-nishimura, I., \& Kohchi, T. (2014). CRISPR/Cas9-mediated targeted mutagenesis in the liverwort Marchantia polymorpha L. Plant ant Cell Physiology, 55(3), 475-481. https://doi.org/10.1093/pcp/pcu014

Sun, H. Y., Song, J., Wang, J. G., Liu, H. L., Sun, J., Mo, T. Y., ... Zou, D. T. (2019). Using CRISPR/Cas9 technology to edit Badh2 gene to improve the flavor of Japonica Rice. Acta Agriculturae Boreali-sinica, 34(4), 1-8.

Sun, Y. W., Jiao, G. A., Liu, Z. P., Zhang, X., Li, J. Y., Guo, X. P., ... Xia, L. Q. (2017). Generation of high-amylose rice through CRISPR/Cas9-mediated targeted mutagenesis of starch branching enzymes. Front Plant Science, 8, 298. https://doi.org/10.3389/fpls.2017.00298

Sun, Y., Zhang, X., Wu, C., He, Y., Ma, Y., Hou, H., ... Xia, L. (2016). Engineering herbicide-resistant rice plants through CRISPR/Cas9-medi-ated homologous recombination of acetolactate synthase. Molecular Plant, 9(4), 628-631. https://doi.org/10.1016/j.molp.2016.01.001

Tang, L., Mao, B., Li, Y., Lv, Q., Zhang, L., Chen, C., ... Zhao, B. (2017). Knockout of OsNramp5 using the CRISPR/Cas9 system produces low $\mathrm{Cd}$-accumulating indica rice without compromising yield. Scientific Reports, $7, \quad 14438$. https://doi.org/10.1038/s41598-017-14832-9 


\section{Mll Macrothink}

Journal of Biology and Life Science

ISSN 2157-6076

2020, Vol. 11, No. 2

Tian, S., Jiang, L., Gao, Q., Zhang, J., Zong, M., Zhang, H., ... Xu, Y. (2017). Efficient CRISPR/Cas9-based gene knockout in watermelon. Plant Cell Reports, 36(3), 399-406. https://doi.org/10.1007/s00299-016-2089-5

Van Embden, J. D. (1991). Insertion element IS987 from Wang, B. K., Zhang, H., Hong, R. K., Zhang, J. W., Yang, R., Luo, Q., \& Zeng, Q. C. (2018). Editing Wx Gene in Rice by CRISPR/Cas9 system. Rice Science in China, 32(1), 35-42.

Wang, F. J., Wang, C. L., Liu, P. Q., Lei, C. L., Hao, W., Gao, Y., ... Zhao, K. (2016b). Enhanced rice blast resistance by CRISPR/Cas9-targeted mutagenesis of the ERF transcription factor gene OsERF922. PLoS One, 11(4), e0154027. https://doi.org/10.1371/journal.pone.0154027

Wang, F. Q., Fang, F. J., Li, W. Q., Zhu, J. Y., Wang, J., Zhong, W. G., \& Yang, J. (2016a). Efficiency analysis of rice Pi21 gene knockout by CRISPR/Cas9. Rice Science in China, 30(5), 469-478.

Wang, L., Wang, L., Tan, Q., Fan, Q., Zhu, H., Hong, Z., ... Duanmu, D. (2016c). Efficient inactivation of symbiotic nitrogen fixation related genes in Lotus japonicus using $\begin{array}{llllll}\text { CRISPR-Cas9. Frontiers in Plant } & \text { Science, } & \text { 7(703), } & 1333 .\end{array}$ https://doi.org/10.3389/fpls.2016.01333

Wang, X., Tu, M., Wang, D., Liu, J., Li, Y., Li, Z., .. Wang, X. (2018). CRISPR/Cas9-mediated efficient targeted mutagenesis in grape in the first generation. Plant Biotechnology Journal, 16(4), 844-855. https://doi.org/10.1111/pbi.12832

Woo, J. W., Kim, J., Kwon, S. I., Corvalán, C., Cho, S. W., Kim, H., ... Kim, J. S. (2015). DNA-free genome editing in plants with preassembled CRISPR-Cas9 ribonucleoproteins. Nature Biotechnology, 33(11), 1162-1164. https://doi.org/10.1038/nbt.3389

Xie, K. B., Minkenberg, B., \& Yang, Y. N. (2015). Boosting CRISPR/Cas9 multiplex editing capability with the endogenous tRNA-processing system. Proceedings of the National Academy of Sciences of the United States of America, 112(11), 3570-3575. https://doi.org/10.1073/pnas.1420294112

Xie, Y., Niu, B., Long, Y., Li, G., Tang, J., Zhang, Y., ... Chen, L. (2017). Suppression or knockout of $\mathrm{SaF} / \mathrm{SaM}$ overcomes the Sa-mediated hybrid male sterility in rice. Journal of Integrative Plant Biology, 59(9), 669- 679. https://doi.org/10.1111/jipb.12564

Xie, Y., Tang, J., Xie, X., Li, X., Huang, J., Fei, Y., ... Chen, L. (2019). An asymmetric allelic interaction drives allele transmission bias in interspecific rice hybrids. Nature Communications, 10(1), 2501. https://doi.org/10.1038/s41467-019-10488-3

Xu, R., Yang, Y., Qin, R., Li, H., Qiu, C., Li, L., ... Yang, J. (2016). Rapid improvement of grain weight via highly efficient CRISPR/Cas9-mediated multiplex genome editing in rice. Journal of Genetics and Genomics, 43(8), 529-532. https://doi.org/10.1016/j.jgg.2016.07.003

Zhang, J. S., Zhang, H., Botella, J. R., \& Zhu, J. K. (2018). Generation of new glutinous rice by CRISPR/Cas9-targeted mutagenesis of the Waxy gene in elite rice varieties. Journal of 
Integrative Plant Biology, 60(5), 369-375. https://doi.org/10.1111/jipb.12620

Zhang, X. H., Tee, L. Y., Wang, X. G., Huang, Q. S., \& Yang, S. H. (2015). Off-target effects in CRISPR/Cas9-mediated genome engineering. Molecular Therapy Nucleic Acids, (4): e264. https://doi.org/10.1038/mtna.2015.37

Zhang, Y., Liang, Z., Zong, Y., Wang, Y., Liu, J., Chen, K., ... Gao, C. (2016). Efficient and transgene-free genome editing in wheat through transient expression of CRISPR/Cas9 DNA or RNA. Nature Communications, 7, 12617. https://doi.org/10.1038/ncomms12617

Zhang, H., Zhang, J., Lang, Z., \& Botella, J. (2017). R. Genome editing: principles and applications for functionalgenomics research and crop Improvement. Critical Reviews Plant Sciences, 36(4), 1-19. https://doi.org/10.1080/07352689.2017.1402989

Zhou, H., He, M., Li, J., Chen, L., Huang, Z., Zheng, S., ... Zhuang, C. (2016). Development of commercial thermo-sensitive genic male sterile rice accelerates hybrid rice breeding using the CRISPR/Cas9-mediated TMS5 editing system. Scientific Reports, 6(22), 37395. https://doi.org/10.1038/srep37395

Zhou, J., Peng, Z., Long, J., Sosso, D., Liu, B., Eom, J. S., .. Yang, B. (2015). Gene targeting by the TAL effector PthXo2 reveals cryptic resistance gene for bacterial blight of rice. The Plant Journal, 82(4), 632-643. https://doi.org/10.1111/tpj.12838

Zhou, Y., Lin, D. Z., \& Dong, Y. J. (2019). CRISPR/Cas9 site-specific editing of glutin gene GluA3 in Rice. Shanghai Journal of Agriculture, 35(1), 22-28.

\section{Copyright Disclaimer}

Copyright for this article is retained by the author(s), with first publication rights granted to the journal.

This is an open-access article distributed under the terms and conditions of the Creative Commons Attribution license (http://creativecommons.org/licenses/by/4.0/). 